\title{
Distribution and significance of norepinephrine in the lateral cochlear wall of pigmented and albino rats *
}

\author{
Kyle E. Rarey ', Muriel D. Ross ' and Charles B. Smith ${ }^{2}$ \\ Departments of 'Anatomy and 'Pharmacologi: University of Michigan, Ann Arbor, MI 48109, U.S.A.
}

(Received 20 April 1981: accepted 10 July 1981)

Picogram quantities of norepinephrine were found in cochlear regions of pigmented and non-pigmented rats. These regions of the cochlca were the modiolus, organ of Corti-osseous spiral lamina and the lateral cochlear wall. The content of norepinephrine in the modiolus and lateral cochlear wall of the pigmented rat was significantly greater than that in areas of the non-pigmented rat. In contrast. there was no statistical difference between the norepinephrine content of the organ of Corti-osseous spiral lamina region of the pigmented rat and that of the albino rat. Since a major difference between the pigmented and albino rats is the presence of melanin-containing melanocytes in the modiolus and lateral cochlear wall region of the pigmented animals. it is possible that norepinephrine is stored in cochlear melanocytes.

Key words: norepinephrine; melanocytes; tyrosinase; melanin: cochlea.

\section{Introduction}

Recently, cochlear tissues of pigmented and non-pigmented animals were analyzed by high-performance liquid chromatography and electrochemical detection for the presence of catecholamines and serotonin [11]. The results of that investigation provided three main findings. First, norepinephrine was the only endogenous biogenic amine detected. Epinephrine, dopamine and serotonin were not present in measurable amounts. Second, the amounts of norepinephrine in the cochlear tissues of pigmented animals (e.g., pigmented rat, $82.6 \pm 5.0 \mathrm{pg} / \mathrm{mg}$ tissue wet wt.; pigmented guinea pig, $40.2 \pm 4.7 \mathrm{pg} / \mathrm{mg}$ tissue wet wt.) were more than twice the amounts present in albinos (albino rat, $34.1 \pm 4.5 \mathrm{pg} / \mathrm{mg}$ tissue wet wt.; albino guinea pig $15.7 \pm 5.1 \mathrm{pg} / \mathrm{mg}$ tissue wet wt.). Third, cochlear norepinephrine content of the albino rat was only partially depleted after either superior cervical ganglionectomy or the administration of reserpine. In previous fluorescent histochemical studies the catecholamine content of cochlear adrenergic nerve terminals has been reported to be markedly or totally depleted under similar experimental conditions

\footnotetext{
* This work was presented in part at the International Symposium on Pathogenesis. Diagnosis and Treatment of Menière's Disease. Düsseldorf. F.R.G., 12-14 May 1980.
} 
$[12,15,17,18]$. However, the substantial amount of norepinephrine $(19.6 \pm 2.6 \mathrm{pg} / \mathrm{mg}$ tissue wet wt.) found in the cochlear tissues $12 \mathrm{~h}$ after pretreatment with reserpine ( $5 \mathrm{mg} / \mathrm{kg}$ ) would suggest that cochlear norepinephrine content is not entirely confined to noradrenergic nerve terminals.

The objective of this present investigation was to determine whether there are differences in the regional distribution of norepinephrine in the cochleas of pigmented and non-pigmented animals.

\section{Materials and Methods}

\section{Sample preparations}

Cochlear tissues were collected from 21 albino rats $(175-200 \mathrm{~g})$ and 12 hooded rats (175-200 g). After decapitation, the otic capsule was removed from the temporal bone and placed in cold $5 \mathrm{mM}$ Tris- $\mathrm{HCl}$ buffer ( $\mathrm{pH} \mathrm{7.4).} \mathrm{With} \mathrm{the} \mathrm{aid} \mathrm{of} \mathrm{a} \mathrm{dissecting}$ microscope, the bony capsular shell of the cochlea was removed and the cochlear tissues were further dissected into three regions (Fig. 1): 1, lateral cochlear wall region; 2, organ of Corti and osseous spiral lamina region; and 3, the modiolar region. Each cochlear region was placed on aluminum foil and weighed on a Model $7500 \mathrm{Cahn}$ electrobalance. Identical regions from six cochleas were pooled per experimental sample. Each pooled sample was homogenized in $200 \mu 1$ of $0.05 \mathrm{M}$ $\mathrm{HClO}_{4}$ to which $25 \mathrm{ng}$ of dihydroxybenzylamine (internal standard) was added. Immediately after centrifugation for $15 \mathrm{~min}$, approximately $25 \mu 1$ of the supernatant were injected into a high-performance liquid chromatography system that was coupled to an electrochemical detection cell.

To verify the sensitivity of the present technique, norepinephrine content was measured in parotid tissues and compared to values that have been reported previously $[10,16]$. Thus, at the time of killing, parotid tissues were collected, pooled and prepared as described above.

Reagents

Reagent grade chemicals used were: 3,4-dihydroxybenzylamine hydrobromide (Aldrich); l-norepinephrine bitartrate hydrate (Calbiochem) and sodium octyl sulfate (Eastman Kodak).

The column eluant used in the high-performance liquid chromatography system contained $0.06 \mathrm{M}$ citric acid, $0.04 \mathrm{M} \mathrm{Na}_{2} \mathrm{HPO}_{4}$ and $0.3 \mathrm{mM}$ sodium octyl sulfate (as described by Felice et al. [4]). Eluant was prepared daily.

\section{Instrumentation}

The high-performance liquid chromatography system was composed of a Waters (Model 6000A) high-performance pump, a Waters (Model U6K) Universal injector and a reverse-phase $\mu$ Bondapak $\mathrm{C}_{18}$ column $(30 \mathrm{~cm} \times 3.9 \mathrm{~mm}$ i.d.). Biogenic amines were detected by a Bioanalytical electrochemical detector, Model LC-10. The potential of the detector electrode was set at $+0.72 \mathrm{~V}$ vs. $\mathrm{Ag} / \mathrm{AgCl}$ reference electrode. The flow rate of the eluant was $0.8 \mathrm{ml} / \mathrm{min}$. The recorder was set at 30 $\mathrm{cm} / \mathrm{h}$. 


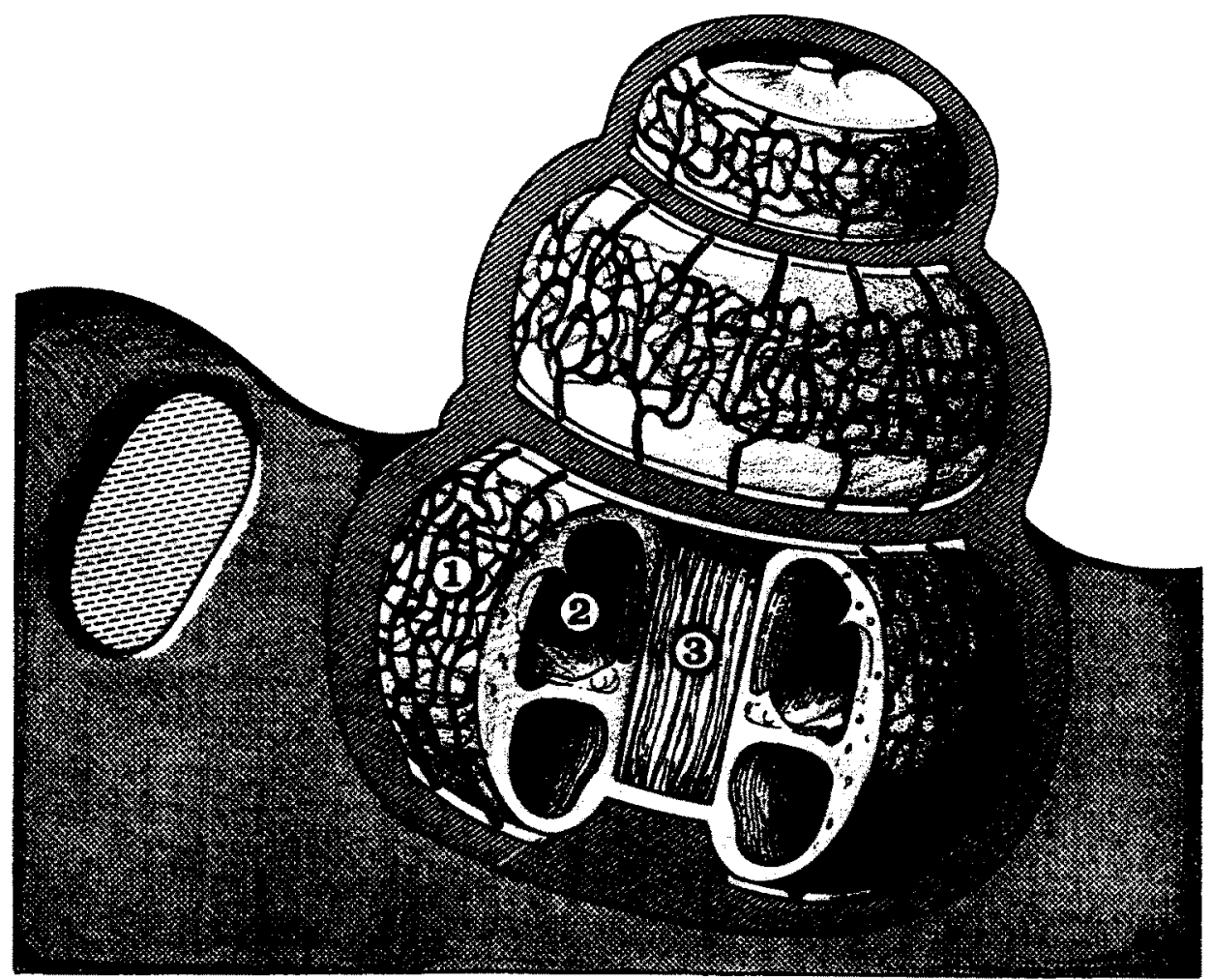

Fig. I. Schematic drawing illustrating the cochlea of the rat following the removal of the bony capsule. The lateral cochlear wall of the basal turn and a portion of the basal modiolar bone have been removed to demonstrate the following regions that were analyzed for norepinephrine content: 1, lateral cochlear wall; 2, organ of Corti and osseous spiral lamina region; 3, modiolar region.

\section{Calculations}

After determination of the ratio of the recorded peak height of the norepinephrine to the peak height of the internal standard, the quantity of norepinephrine of each sample was extrapolated from a standard curve that was prepared daily. All results are expressed as mean values \pm the standard error of the mean. Statistical significance was determined by the use of Student's $t$-test and $P$ values are given in parentheses.

\section{Results}

Regional concentration of norepinephrine in the cochlea and parotid gland of the hooded rat

Endogenous norepinephrine was quantitatively detected in all cochlear regions and the parotid gland of the hooded rat. Typical chromatograms of norepinephrine 
measured in the three regions of the cochlea and parotid gland are illustrated in Fig. 2. The norepinephrine content (pg/mg tissue wet wt.) of each cochlear region was: lateral cochlear wall, $188.35 \pm 9.86(n=4)$; organ of Corti and osseous spiral lamina, $166.46 \pm 6.91(n=4)$; modiolar tissues, $111.39 \pm 12.08(n=4)$. The amount of norepinephrine detected in the parotid gland was $1234.26 \pm 190.99 \mathrm{pg} / \mathrm{mg}$ tissue wet wt. $(n=4)$.

Statistically significant differences were found between the amount of norepinephrine in the lateral cochlear wall and that in the modiolar region $(P<$ 0.005 ), and between the level of norepinephrine in the modiolus and that in the organ of Corti-osseous spiral laminar region $(P<0.005)$ (see Fig. 3). However, there was no significant difference between the amount of norepinephrine in the lateral cochlear wall and that in the organ of Corti-osseous spiral lamina region $(P<0.1)$.

Regional concentrations of norepinephrine in the cochlea and parotid gland of the albino rat

Regional tissue samples of the albino rat cochleas were analyzed, and norepinephrine was found again in all regional samples. The concentration of

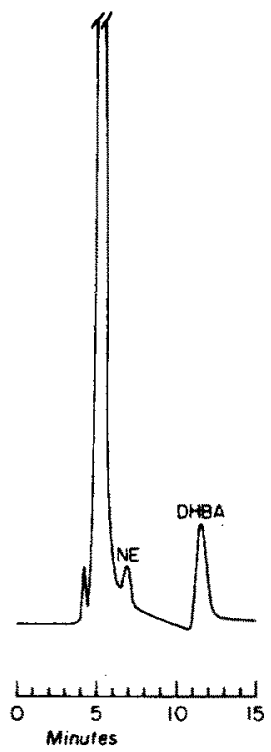

(20)

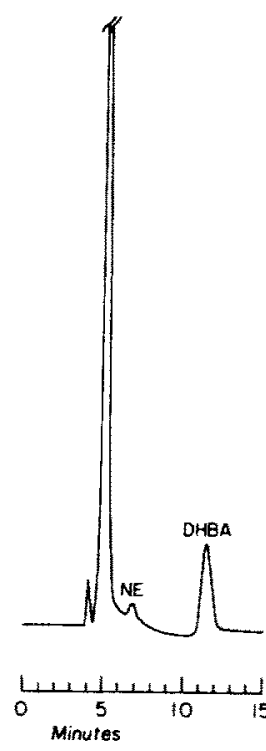

(26)

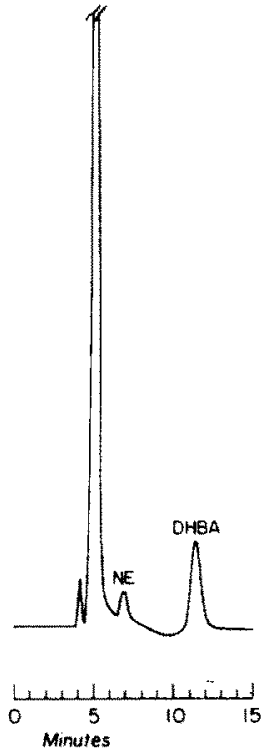

(20)

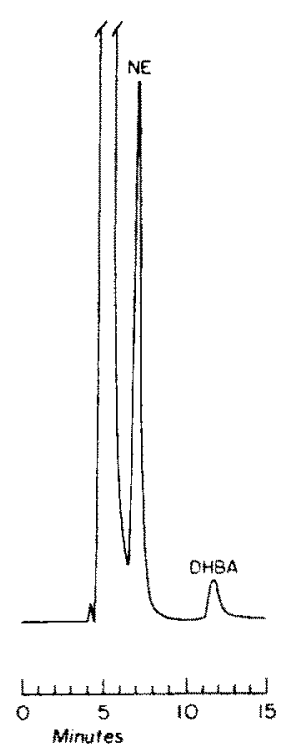

(2d)

Fig. 2. Representative chromatograms of norepinephrine measured in the lateral cochlear wall (a), organ of Corti-osseous spiral lamine region (b), modiolar region (c) and parotid gland (d) of the hooded rat. The chromatographic conditions were: (A) stationary phase, $30 \mathrm{~cm} \times 3.9 \mathrm{~mm}$ i.d. $\mu$ Bondapak $\mathrm{C}_{18}$ (Waters Assoc.); (B) mobile phase, citric acid-phosphate eluant as described in text; (C) flow rate, $0.8 \mathrm{ml} / \mathrm{min}$; (D) temperature, ambient; (E) amount injected: $25 \mu 1$ of each regional cochlear pooled sample and $10 \mu 1$ of pooled parotid gland sample; (F) electrode potential, $+0.72 \mathrm{~V}$ vs. $\mathrm{Ag} / \mathrm{AgCl}$ reference electrode; (G) recorder sensitivity, I V, $10 \mathrm{nA} ;(\mathrm{H})$ recorder rate, $30 \mathrm{~cm} / \mathrm{h}$. 
norepinephrine ( $\mathrm{pg} / \mathrm{mg}$ tissue wet wt.) in each region was: lateral cochlear wall, $98.2 \pm 23.07(n=7)$; organ of Corti-osseous spiral lamina, $131.37 \pm 27.15(n=7)$; modiolar tissues, $60.93 \pm 11.16(n=7)$. The norepinephrine content of the parotid gland was $828.82 \pm 189.93 \mathrm{pg} / \mathrm{mg}$ tissue wet wt. $(n=7)$.

There was a significant difference between the amount of norepinephrine in the modiolus and that in the organ of Corti-osseous spiral laminar region $(P<0.05)$ (see Fig. 4). However, there was no significant difference between the amount of norepinephrine in the lateral cochlear wall and either that in the modiolar region or that in the organ of Corti-osseous spiral laminar region.

Regional concentrations of norepinephrine: pigmented versus albino

When the regional concentrations of norepinephrine in cochleas of the hooded rat were compared to the amounts present in the albino rats (Fig. 5), unequal distributions of norepinephrine were observed. The concentrations of norepinephrine in the lateral wall and modiolar regions of the pigmented rat cochleas were approximately twice the levels of norepinephrine in corresponding regions of the albino rats. There was, however, no statistically significant difference between the amounts of norepinephrine present in the organ of Corti-osseous spiral lamina regions of the pigmented and albino rats.

When the norepinephrine content in the parotid gland of the hooded rat was

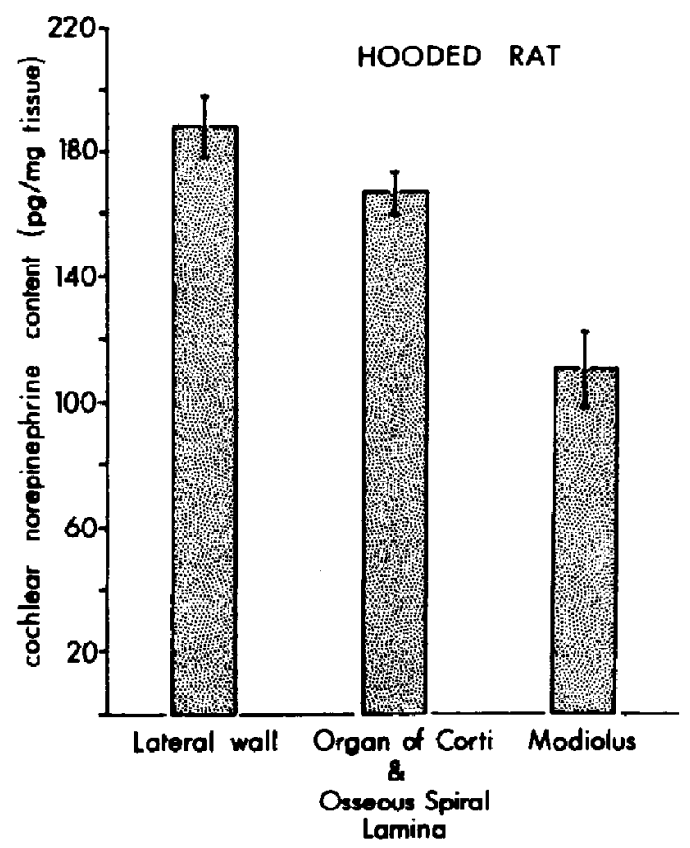

Fig. 3. The regional distribution of norepinephrine detected in hooded rat cochleas. Each bar represents the mean value of norepinephrine and the vertical line represents the standard error. 


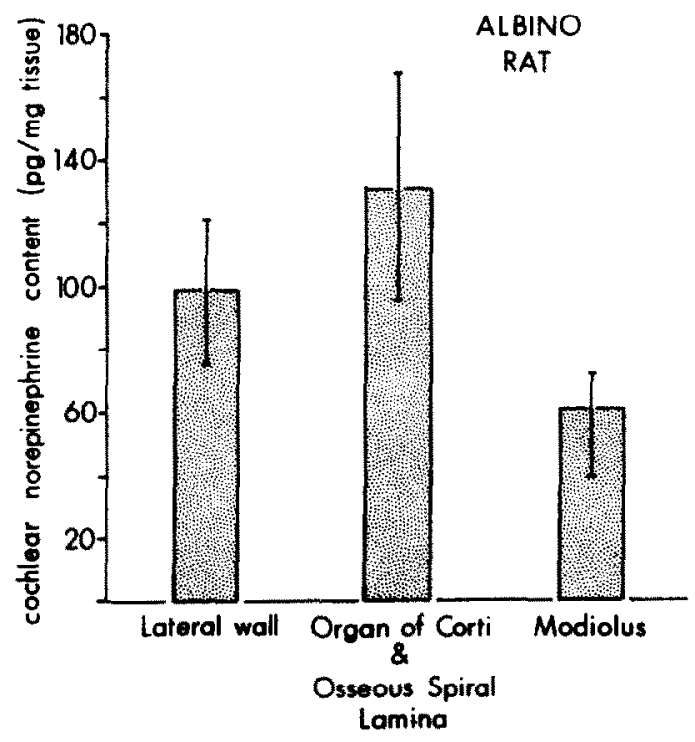

Fig. 4. The regional concentrations of norepinephrine measured in albino rat cochleas. Each bar represents the mean value of norepinephrine content and the vertical line represents the standard error.

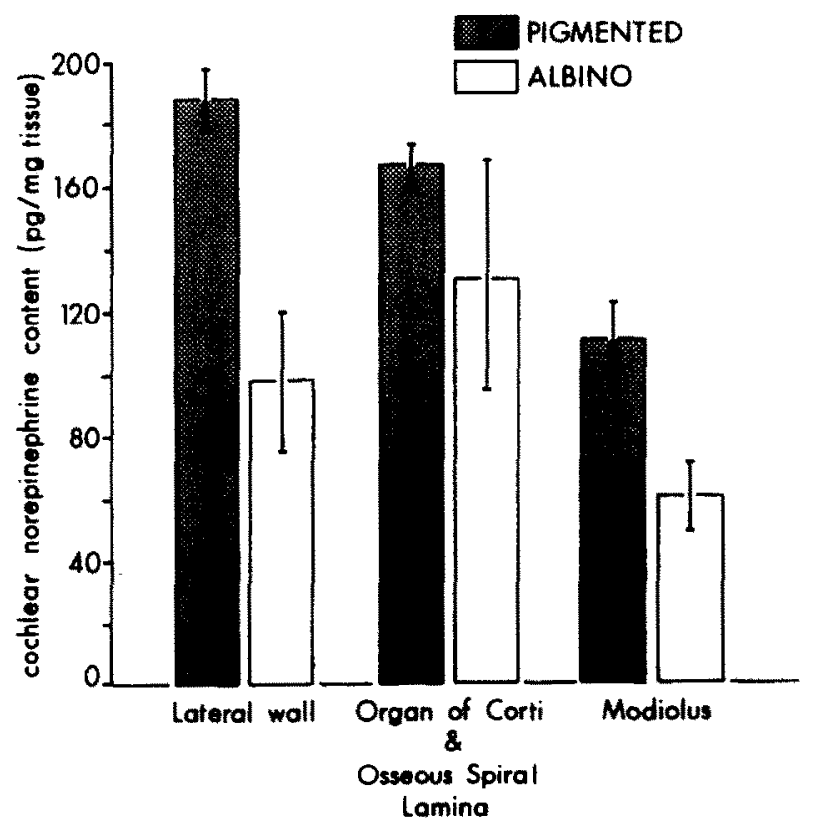

Fig. 5. The regional distribution of norepinephrine in the hooded rat cochleas compared to that in the albino rat cochleas. Each bar represents the mean value of norepinephrine and the vertical line represents the standard error. 
compared to the amount measured in the parotid gland of the albino rat, no statistically significant difference was demonstrated.

\section{Discussion}

The results of this investigation indicate that there is a regional distribution of norepinephrine in the cochleas of both pigmented and non-pigmented rats. The fact that the norepinephrine content measured in the parotid glands of pigmented and albino rats by the present technique closely approximate values reported in previous studies that used spectrofluorometric methods $(1040 \mathrm{pg} / \mathrm{mg}$ [16], $1240 \mathrm{pg} / \mathrm{mg}$ [10]) suggests that high-performance liquid chromatography with electrochemical detection accurately measures the picogram quantities of norepinephrine in the cochlear regions of pigmented and non-pigmented rats.

Interestingly, norepinephrine was found in the lateral cochlear wall. Previous fluorescent histochemical and morphological studies have suggested that there are no noradrenergic nerve terminals present in the lateral wall $[15,17,18]$. Thus, the measured norepinephrine would appear to be associated with a non-neuronal cell population. Cells which Hilding $[5,6]$ described as chromaffin cells would have been the most likely candidates. However, the existence of such cells has never been corroborated.

An alternative cell population in the lateral wall that might contain non-neuronal norepinephrine is that of the cochlear melanocytes which are distributed along the lateral wall vasculature, particularly in the stria vascularis. Cochlear melanocytes are present also in the modiolus. The results of this investigation indicate that endogenous norepinephrine is more concentrated in the modiolar and lateral wall regions of the pigmented rats than in non-pigmented rats. Thus, these data strongly suggest that a portion of the non-neuronal norepinephrine might be associated with the cochlear melanocyte population in the pigmented rats.

It has been demonstrated that in vitro norepinephrine can bind reversibly to the melanin granules of melanocytes. Ishii and Friede [8] have reported the in vitro binding of labeled norepinephrine to melanin-containing neurons of human brain slices. Labeled norepinephrine also accumulates in melanin-containing structures of the pigmented mouse as demonstrated by whole body autoradiography [9]. Thus, it was postulated that melanin of melanocytes might act as reservoirs for such biogenic amines as norepinephrine [9].

The binding of norepinephrine with melanin is presumably based upon the ability of melanin to exist in a stable radical form that can act as a cationic exchange substance $[3,19]$. Interestingly, premelanosomes of melanocytes in both pigmented and albino animals contain the enzyme, tyrosinase, that also can act as a cationic exchange substance [2]. Since concentrations of norepinephrine were measured in the cochleas of albino rats, perhaps the tyrosinase of premelanosomes in the cochlear albino melanocytes (as demonstrated by Hilding and Ginzberg [7]) also acts as a reservoir for norepinephrine.

Certain cells in the body, such as the acinar cells of the parotid gland, can be 
stimulated by norepinephrine to secrete $\mathrm{K}^{+}$, and secondarily water $[1,14]$. In contrast, following a chemical sympathectomy and, thereby, in the absence of norepinephrine, the fluid transport activity of the epithelial cells of Reissner's membrane was reported to be inhibited [13]. Thus, ionic and fluid regulation of certain labyrinthine cells may be directly or indirectly under the influence of norepinephrine. An alteration in the cochlear level of norepinephrine, therefore, might induce inner ear dysfunction. Thus, cochlear tissue levels of norepinephrine should be taken into consideration when assessing microhomeostatic disorders of the inner ear.

\section{Acknowledgement}

We wish to thank Mr. Roger Sacks and Mr. William Brudon for the preparation of diagrams used in this report. This work was supported by National Research Service Award 1 F32 NS 06151 NEUB.

\section{References}

I Batzri, S., Selinger, Z., Schramm, M. and Robinovitch, M.R. (1973): Potassium release mediated by the epinephrine $\alpha$-receptor in rat parotid slices. J. Biol. Chem. 248, 361-368.

2 Bersin, T. (1957): Exchange adsorption in man. In: Ion Exchangers in Organic and Biochemistry. Ch. 26. Editors: C. Calmon and T.R.E. Kressman. Interscience, New York.

3 Edelstein, L.M. (1971): Melanin: a unique biopolymer. In: Pathobiology Annual, Vol. I, pp. 309-324. Editor: H.L. Ioachim. Appleton-Century-Crofts Educational Division. Meredith Corporation. New York.

4 Felice, L.J., Felice, J.D. and Kissinger. P.T. (1978): Determination of catecholamines in rat brain parts by reverse-phase ion-pair liquid chromatography. J. Neurochem. 31, 1461-1465.

5 Hilding, D.A. (1964): Catecholamine activity in the inner ear: histochemical study by clectron microscopy. J. Acoust. Soc. Am. 36, 1016 (abstract).

6 Hilding, D.A. (1965): Cochlear chromaffin cells. Laryngoscope $75,1-15$.

7 Hilding. D.A. and Ginzberg. R.D. (1977): Pigmentation of the stria vascularis. Acta Otolaryngol. 84. $24-37$.

8 Ishii, T. and Friede, R. (1968): Tissue binding of tritiated norepinephrine in pigmented nuclei of human brain. Am. J. Anat. 122, 139-144.

9 Lindquist, N.G. (1973): Accumulation of drugs in melanin. Acta Radiol. Diagn. Suppl. 325, 1-92.

10 Mark, M.R. (1979): The Role and the Autonomic Nervous System in Regulation of the Structural and Functional Status of the Rat Parotid Gland. Ph.D. Thesis. University of Michigan. Ann Arbor, Mich.

II Rarey, K.E., Ross. M.D. and Smith. C.B. (1981): Quantitative evidence for cochlear, non-neuronal norepinephrine. Hearing Res. 5, 101-108.

12 Ross, M.D. (1969): Orange fluorescence in the acoustic nerve. J. Histochem. Cytochem. 17. 814-820.

13 Ross, M.D. (1978): Glycogen accumulation in Reissner's membrane following chemical sympathectomy with 6-hydroxydopamine. Acta Otolaryngol. 86, 314-330.

14 Selinger. Z.. Batzri. S.. Eimeral. S. and Schramm. M. (1973): Calcium and energy requirements for K ${ }^{+}$ release mediated by the epinephrine $\alpha$-receptor in rat parotid slices. J. Biol. Chem. 248, 369-372.

15 Spoendlin, H. and Lichtensteiger, W. (1966): The adrenergic innervation of the labyrinth. Acta Otolaryngol. 61, 423-434.

16 Strömblad, B.C.R. and Nickerson, M. (1961): Accumulation of epinephrine and norepinephrine by some rat tissues. J. Pharmacol. Exp. Therap. 134, 154-159. 
17 Terayama. Y.. Holz. E. and Beck, C. (1966): Adrenergic innervation of the enchlea. Ann. Otol. 75. $69-86$.

18 Terayama, Y., Yamamoto, K. and Sakamoto. T. (1968): Electron microscopic observations on the postganglionic sympathetic fibers in the guinea pig cochlea. Ann. Otol, 77, 1152-1170.

19 White, L.P. (1958): Melanin: a naturally occurring cation exchange material. Nature (London) 182. $1427-1428$. 